\title{
A simplified physically based coupled rainfall threshold model for triggering landslides
}

\author{
Yu-ming Wu ${ }^{\text {a,b,c }}$, Heng-xing Lan ${ }^{\mathrm{a}, *}$, Xing Gao ${ }^{\mathrm{a}}$, Lang-ping $\mathrm{Li}^{\mathrm{a}, \mathrm{c}}$, Zhi-hua Yang ${ }^{\mathrm{a}}$

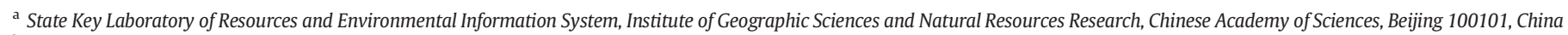 \\ ${ }^{\mathrm{b}}$ Key Laboratory of Geohazard Prevention of Hilly Mountains, Ministry of Land and Resources, Fuzhou 350002, China \\ c University of Chinese Academy of Sciences, Beijing 100049, China
}

\section{A R T I C L E I N F O}

\section{Article history:}

Received 14 November 2014

Received in revised form 10 March 2015

Accepted 22 May 2015

Available online 27 May 2015

\section{Keywords:}

Rainfall threshold

Physically based coupled model

Infinite slope stability model

Darcy's law

Shallow landslides

\begin{abstract}
A B S T R A C T
A number of rainfall threshold models for triggering landslides have been developed in either empirical or physical manner. The objective of an empirical rainfall threshold model is to establish a relationship between rainfall intensity and duration, which is a line on a log-log diagram, although the mechanism of the relationship following the power law is not yet well understood. The sufficiency of rainfall and landslide data is also a significant concern for empirical models. A simplified physically based rainfall threshold model is developed by coupling the Mohr-Coulomb law and Darcy's law based on the assumptions that the slope has an infinite length and that discrete water diffusion is physically based. The power-law mechanism for the relationship between rainfall intensity and duration for the initiation of a landslide is investigated using this physically based model. The rainfall threshold calculated with the model shows that the threshold follows the power law for short rainfall durations whereas it gradually tends towards a constant value for long rainfall durations. Case studies have shown that a plausible threshold for regions that lack sufficient landslide and rainfall data can be obtained via the model. The model is also applied to cases which occurred in regions geologically typical of Fujian Province, southeast China. The landslide distribution predicted by our model accords with the interpretation of high resolution satellite imagery, and this suggests that the proposed physically based model also effectively determines rainfall thresholds for triggering regional landslides.
\end{abstract}

(c) 2015 Elsevier B.V. All rights reserved.

\section{Introduction}

Rainfall-induced landslides are common in the southeast coastal areas of China. Typhoons carrying heavy rainfall from April to September can lead to landslides on a large-scale, which pose a severe threat to public safety (Wu et al., 2014). Thus, the prediction of rainfallinduced landslides is quite significant for these areas. Rainfall threshold is a lower boundary for triggering landslides and is essential for prediction of storm-induced landslides because there is an empirical relationship between rainfall threshold and landslides. There are multiple forms of rainfall threshold, e.g., intensity-duration (Caine, 1980; Guzzetti et al., 2007, 2008), daily precipitation (Crozier, 1999; Glade et al., 2000), and event rainfall (Bell and Maud, 2000). The form of a rainfall threshold is determined by monitoring equipments and local rainfall characteristics.

The rainfall threshold for landslides can be determined by two types of models: empirically based and physically based models (Guzzetti et al., 2007; Martelloni et al., 2012). Empirically based models are

\footnotetext{
* Corresponding author at: State Key Laboratory of Resources and Environmental Information System, Institute of Geographic Sciences and Natural Resources Research, Chinese Academy of Sciences, 11A Datun Road, Chaoyang District, Beijing 100101, China.

E-mail addresses: lanhx@igsnrr.ac.cn, lanhx@lreis.ac.cn (H. Lan).
}

popular due to their simplicity. Most regional rainfall thresholds for triggering landslides are obtained by empirically based models (Aleotti, 2004; Caine, 1980; Guzzetti et al., 2008). The empirical rainfall threshold that is most commonly used is based on the relationship between rainfall intensity and duration, which is a line on a log-log diagram. Although intensive research demonstrates that the rainfall threshold for triggering landslides drops exponentially, the physical mechanisms associated with this phenomenon have not been made clear.

However, the empirically based model cannot give an accurate rainfall threshold with insufficient landslide information. Physically based models have been providing the best way to solve the problem, they are able to predict the time of landslides' possible occurrence, as well as their location. Models of this type take into account the dominant mechanical processes of landslides. Mechanical parameters, such as cohesion and friction angle, are involved. SINMAP (Pack et al., 1998; Terhorst and Kreja, 2009) and TRIGRS (Baum et al., 2002, 2005; Kim et al., 2010; Liao et al., 2011) are two widely used physically based models which use Factor of Safety as a criterion to evaluate landslides. However, these models cannot provide a rainfall threshold for triggering landslides in regions or for a specific landslide.

The Critical RainFall (CRF) model (Salciarini et al., 2008), a module of TRIGRS (Baum et al., 2002), which provides an intensity-duration threshold, can solve this problem. The assumption of the CRF model is 
that the peak pore pressure head on the failure surface is at the end of rainfall period. The CRF-v2 model (Salciarini et al., 2012) is an improved version of the CRF model. In the CRF-v2 model it is considered that the pressure head on the failure surface reaches a peak that is not at the end of the rainfall event. Thus, the CRF-v2 model provides more realistic results than the CRF model. However, the rainfall threshold calculated using the CRF models is slightly lower than that observed for long duration, since the model for long duration neglects lateral pore pressure transmission. Thus, these models are not suitable for predicting rainfall thresholds for triggering landslides for sites stricken by long-lasting rains. In addition, a daily rainfall threshold is more useful for predicting landslides in some regions, especially those where hourly rainfall data are lacking, and the CRF models cannot reflect changes in daily rainfall threshold upon changes in rainfall.

Obtaining the rainfall threshold is very difficult. This is because rainfall processes are complicated, and the soil parameters have uncertainties. Therefore, a Monte Carlo simulation was adopted to address the complexities of rainfall processes and the variability of soil parameters (Peres and Cancelliere, 2014). However, considering the time required for calculating the rainfall threshold at each cell, the MonteCarlo approach is not suitable for determining rainfall thresholds for a region.

The aim of this study is to enhance the adaptive capacity of a physically based model and determine a rainfall threshold with a change in rainfall. Then, due to the decrease in effective stress and strength resulting from pore pressure, and we assume that the rainfall threshold is related to the ratio of the height of the saturated layer to the height of the sliding body and that water can infiltrate easily into the soil through macro-pores and cracks whereby the rainfall threshold on different spatial and time scales can be obtained via the model. A specific landslide and a region were selected for validating the proposed model. In addition, we intend to explain why the relationship between rainfall intensity and rainfall duration from our proposed physically based model differs a little from the relationship which the traditional power law indicates.

\section{Theoretical model}

For shallow landslides, the failure surface is approximately parallel to the slope surface and the bedrock can be considered impermeable (Chang et al., 2014; Pack et al., 1998). As most of the rainfall can easily infiltrate into the deeper parts of channels through the cracks and failure surfaces (Montrasio and Valentino, 2008), rainfall, which can influence the pore water pressure on a crack or failure surface, is an important triggering factor.

The infinite-slope model (Fig. 1) is therefore adopted in this work. Factor of Safety $\left(F_{s}\right)$, is defined by the ratio of the stabilizing force $F_{r}$ to the destabilizing force $F_{d}$. The stabilizing force $F_{r}$ is calculated by the Mohr-Coulomb strength criterion, and the destabilizing force $F_{d}$ is the

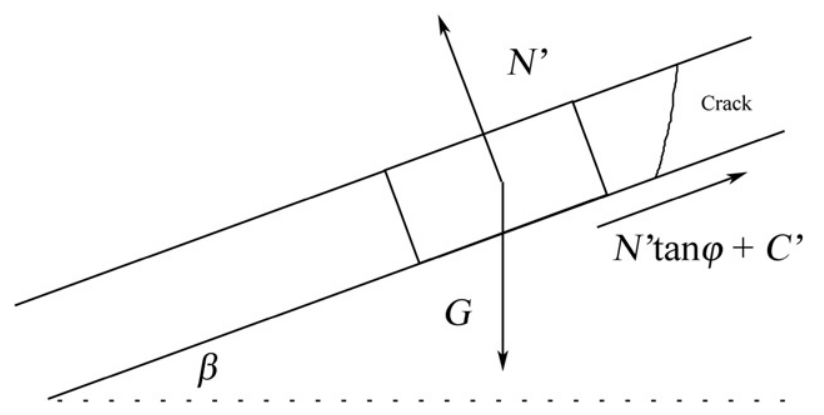

Fig. 1. Diagram of a single slice of an infinite slope with acting forces. sum of the gravitational forces along the slope and the seepage force. The expression for Factor of Safety is:

$F_{s}=\frac{F_{r}}{F_{d}}=\frac{N^{\prime} \tan \varphi+C^{\prime}}{G \sin \beta+F^{\prime}}$

where $N^{\prime}$ is the normal effective force, $C^{\prime}$ is the effective cohesion, $\varphi$ is the friction angle, $G$ is the weight of the sliding body including both soil and water, $\beta$ is the slope of slip surface and $F^{\prime}$ is the seepage force.

The expression of $G$ (Fredlund and Rahardjo, 1993), under the assumption that the effective stress is equal to the total stress, is:

$G=\gamma_{w} \cdot \cos \beta \cdot H \cdot \Delta s \cdot\left[m(n-1)+G s(1-n)+n \cdot S_{r}(1-m)\right]$

in which $H$ is the thickness of the sliding body, $\Delta s$ is the area of the sliding surface, $m$ is the dimensionless thickness of the saturated layer which lies between 0 and $1, n$ is the porosity, Gs is the specific weight and $S_{r}$ is the degree of saturation of the soil. Then, the expression of $N^{\prime}$ is:

$N^{\prime}=G \cdot \cos \beta=\gamma_{w} \cdot \cos ^{2} \beta \cdot H \cdot \Delta s \cdot\left[m(n-1)+G s(1-n)+n \cdot S_{r}(1-m)\right]$

The seepage force $F^{\prime}$ can be expressed as:

$F^{\prime}=\gamma_{w} \cdot \sin \beta \cdot \cos \beta \cdot m \cdot H \cdot \Delta s$

where $\gamma_{w}$ is the unit weight of the water. The effective cohesive force is:

$C^{\prime}=c^{\prime} \cdot \Delta s$.

Then, substituting Eqs. (2), (3), (4) and (5) into Eq. (1), we have:

$F_{S}=\frac{\cot \beta \cdot\left[m(n-1)+G s(1-n)+n \cdot S_{r}(1-m)\right] \tan \varphi+\frac{2 c^{\prime}}{\sin 2 \beta \cdot H \cdot \gamma_{w}}}{\left[m(n-1)+G s(1-n)+n \cdot S_{r}(1-m)\right]+m}$.

When a landslide is in a critical condition, i.e., $F_{s}=1$, a critical dimensionless thickness of the saturated layer $m_{c r}$ is given by:

$m_{c r}=\frac{(\cot \beta \tan \varphi-1)\left[G s \cdot(1-n)+n \cdot S_{r}\right]+\frac{2 c^{\prime}}{\sin 2 \beta \cdot H \cdot \gamma_{w}}}{n \cdot\left(1-S_{r}\right)-\left[n \cdot\left(1-S_{r}\right)-1\right] \cot \beta \tan \varphi}$.

The slope is stable when $m<m_{c r}$ and unstable when $m>m_{c r}$. As $0 \leq m \leq 1$, the slope will always be stable under any rainfall condition if $m_{c r}>1$, while the slope will be unstable even under dry conditions if $m_{c r}<0$.

In real situations, as rainfall depth $\left(h_{i}\right)$ was recorded by the interval $\Delta t$ which is commonly either $1 \mathrm{~h}$ or $1 \mathrm{~d}, m$ can be expressed by each increment of rainfall depth $\left(h_{i}\right)$. Therefore, a model adopting Darcy's law (Montrasio and Valentino, 2008; Montrasio et al., 2009, 2012) was used to calculate the evolution of $m$ during the rainfall process. In the model, assuming the current time is $t_{0}$ and the dimensionless thickness of the saturated layer at $t_{0}$ is $m_{0}$, the contribution of rainfall at $t_{i}$ to $m_{0}$, which is denoted by $m_{i, 0}$, will be:

$m_{i, 0}=\frac{h_{i-1, i}}{n \cdot H \cdot\left(1-S_{r}\right)} \cdot \exp \left[-k \cdot \frac{\sin \beta}{n \cdot\left(1-S_{r}\right)}\left(t_{0}-t_{i}\right)\right],(i=0,-1,-2, \ldots)$

where $k$ is the infiltration rate. This equation suggests that the contribution of the rainfall between $t_{i-1}$ and $t_{i}$ to $m_{0}$ decreases exponentially 
with the increase of time span between $t_{i}$ and $t_{0}$. Taking the sum of all of the $m_{i, 0}$, we have:

$m_{0}=\sum_{i=-\infty}^{0} m_{i, 0}=\sum_{i=-\infty}^{0} \frac{h_{i-1, i}}{n \cdot H \cdot\left(1-S_{r}\right)} \cdot \exp \left[-k \cdot \frac{\sin \beta}{n \cdot\left(1-S_{r}\right)}\left(t_{0}-t_{i}\right)\right]$.

The negative infinity implies that all of the rainfall before the current time has contributed to $m_{0}$. However, the effects of past rainfall events on $m_{0}$ are negligible owing to the negative exponential item in Eq. (8). A transformation of Eq. (9) gives:

$m_{0}=m_{0,0}+\sum_{i=-\infty}^{-1} m_{i, 0}$

That is to say, if we expect to have a critical condition for the landslide at $t_{0}$, the following condition must be met:

$m_{0,0}=m_{c r}-\sum_{i=-\infty}^{-1} m_{i, 0}$

In other words, if we know the rainfall background before $t_{-1}$, the rainfall between $t_{-1}$ and $t_{0}\left(h_{-1,0}\right)$ required for inducing a critical condition for the landslide at $t_{0}$ can be calculated. The equation to calculate the critical rainfall between $t_{-1}$ and $t_{0}$ is obtained by substituting Eq. (11) into Eq. (8):

$h_{-1,0}=n \cdot H \cdot\left(1-S_{r}\right) \cdot\left(m_{c r}-\sum_{i=-\infty}^{-1} m_{i, 0}\right)$.

This model takes into account a flow parallel to the slope and simplified the complicated mechanisms using an exponential negative law. In the following sections, this model will be compared with other models including both physical models and empirical models. According to Eq. (12), the rainfall threshold for triggering landslides changes with the antecedent rainfall. If rainfall is uniform, the rainfall intensity that can trigger a landslide is:

$h=n \cdot H \cdot\left(1-S_{r}\right) \cdot m_{c r}\left[\sum_{i=-\infty}^{0} \exp \left(k \cdot \frac{\sin \beta}{n \cdot\left(1-S_{r}\right)} \cdot i \cdot \Delta t\right)\right]^{-1},(i=0,-1,-2, \ldots)$.

\section{Model application to a specific landslide}

The Hedangwei landslide (Fig. 2), located in the north of the Yushang Village, Taining County, Fujian Province, China, is the landslide investigated in this study. This landslide had been triggered twice by heavy rainfalls on June 21, 2005 and June 18, 2010. On June 21, 2005, cracks appeared at the site and the slide occurred two days later.

The Hedangwei landslide consists of two sub-slides (Fig. 2). The slope of the slipping surface of the Hedangwei landslide is about $28^{\circ}$. The thickness of each of the two slide bodies is $2 \mathrm{~m}$. In this section, we

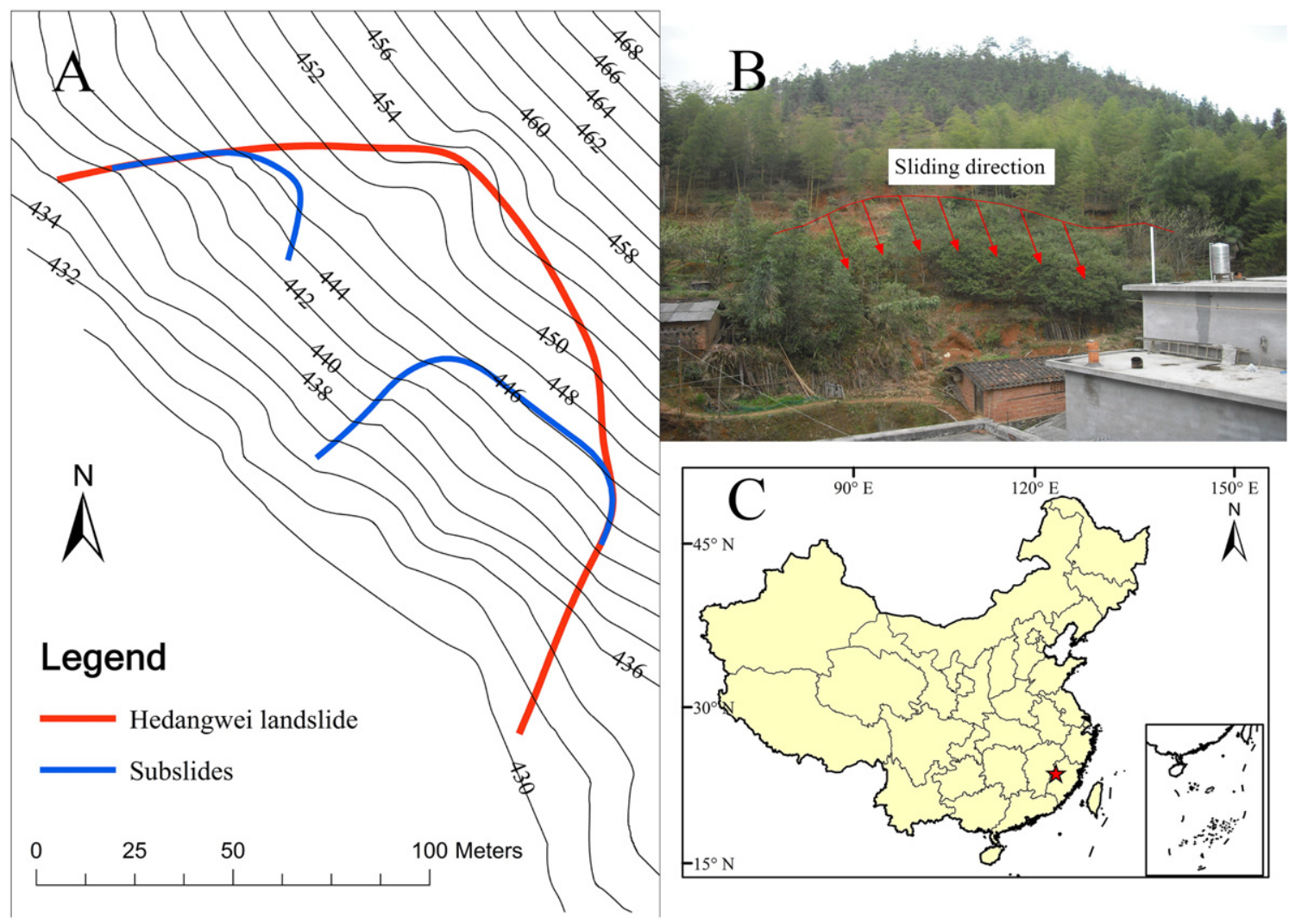

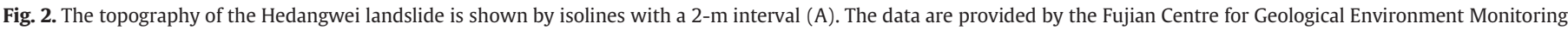

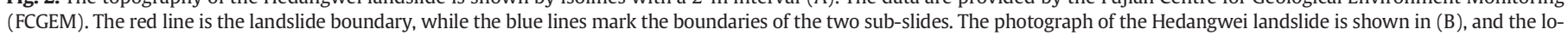
cation of the Hedangwei landslides in China is shown in (C) and the red star is the location of the Hedangwei landslide. 
first use our model to estimate the hourly and daily rainfall thresholds of the Hedangwei landslide and then compare our estimates with the results of other models. According to the field investigation, the topsoil is residual soil and the rock layer mainly consists of metasandstone. The underground water at the site has not been found.

\subsection{Hourly rainfall threshold}

The critical dimensionless thickness of the saturated layer $m_{c r}$ for the Hedangwei landslide was calculated using Eq. (7). The soil parameters used in our model are listed in Table 1.

The measurements of the drilling samples were made by the Fujian Centre for Geological Environment Monitoring (FCGEM) (Fig. 3). Table 1 shows that soil parameters in Caiyuan were measured for 6 soil samples. In the measurement, the cohesion $(c)$ and friction angle $(\varphi)$ were measured in the saturated state. The porosity $n$ can be expressed by

$n=\frac{e}{1+e}$

Gs is expressed by

$G s=\frac{\gamma(1+e)}{\gamma_{w}(1+w)}$

and saturation degree $\left(S_{r}\right)$ is

$S_{r}=\frac{w \cdot G_{s}}{e}$.

In Eq. (15), the specific weight of water $\gamma_{w}$ is $10 \mathrm{kN} / \mathrm{m}^{3}$.

We assume that the rainfall is uniform during the rainfall event. The required rainfall intensities for triggering the Hedangwei landslide for different rainfall durations were calculated using Eq. (13). In addition, the rainfall thresholds for the Hedangwei landslide were also estimated using the CRF-v2 model (Salciarini et al., 2012). All of the thresholds estimated using the different models are presented in intensityduration curves in Fig. 4.

The Generalized Extreme Value (GEV) distribution (Floris and Bozzano, 2008) was used to detect the critical rainfall durations regarding the two historical landslide events. The critical duration is the most exceptional rainfall duration with the lowest probability of cumulative rainfall and is thus assumed to be the rainfall event that triggered the landslide. For the landslide event on June 18, 2010, the detected critical duration is $24 \mathrm{~h}$ during which the average rainfall intensity is $5.46 \mathrm{~mm} / \mathrm{h}$. For the landslide event on June 21, 2005, the detected critical duration is $96 \mathrm{~h}$ during which the average rainfall intensity is $5.23 \mathrm{~mm} / \mathrm{h}$. According to the estimated critical rainfall durations and rainfall intensities, the two historical landslide events are plotted in Fig. 4.

The models vary with the timescale (Iverson, 2000). In the shortterm behavior, slope-normal pore pressure transmission plays an

Table 1

Statistics of the soil parameters in the Hedangwei landslide.

\begin{tabular}{llllcl}
\hline & $\begin{array}{l}w^{\mathrm{a}} \\
(\%)\end{array}$ & $\begin{array}{l}\gamma^{\mathrm{b}} \\
\mathrm{kN} / \mathrm{m}^{3}\end{array}$ & $e^{\mathrm{c}}$ & $\begin{array}{l}c^{\mathrm{d}} \\
\mathrm{kPa}\end{array}$ & $\begin{array}{l}\varphi^{\mathrm{e}} \\
\left(^{\circ}\right)\end{array}$ \\
\hline Min & 30.4 & 17.5 & 0.843 & 9 & 18.5 \\
Max & 38.6 & 18.7 & 1.068 & 23 & 31.4 \\
Mean & 34.8 & 18.1 & 0.984 & 13.33 & 25.0 \\
SV $^{\mathrm{f}}$ & 32.74 & 17.8 & 0.928 & 10.28 & 22.05 \\
\hline
\end{tabular}

a $w$ is water content.

b $\gamma$ is specific weight.

c $e$ is void ratio.

d $c$ is cohesion in the saturation state.

e $\varphi$ is friction angle in the saturation state.

${ }^{f}$ SV are suggested values offered by the Fujian Centre for Geological Environment Monitoring.

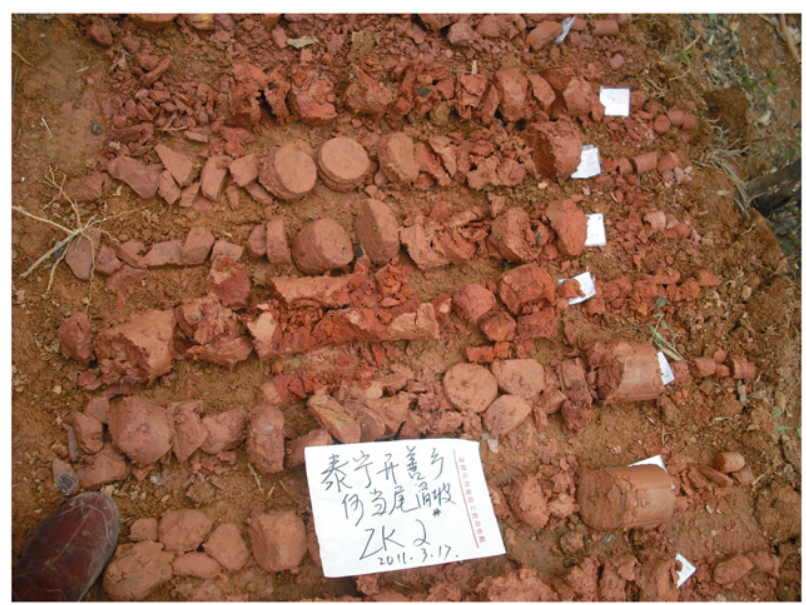

Fig. 3. The drill samples measured by the Fujian Centre for Geological Environment Monitoring.

important role for triggering landslides, and lateral pore pressure transmission can be neglected. In the long-term behavior, slope-normal pore pressure transmission can be neglected. However, the CRF-v2 model assumes a short-term behavior model. Therefore, the rainfall threshold calculated by the CRF-v2 model is underestimated for the long duration. In this work, the assumption of our model is that there are some cracks and macro-pores, and water can infiltrate very easily into the slipping surface. In our model, the dimensionless thickness of the saturated layer was calculated based on Darcy's law. Darcy's law describes steady-state groundwater flow, thus it is applicable for long-term rainfall processes. As a result, for long-term rainfall processes, the trend of rainfall thresholds calculated by our model matches with the trend of records. Our model predicts that the rainfall threshold gradually becomes steady as the rainfall duration increases (Fig. 4). When the rate of water diffusion becomes equal to the rainfall intensity, the dimensionless thickness of the saturated layer $m$ will not increase. If the soil is saturated, the rainfall threshold will be divorced from rainfall intensity, and the rainfall threshold will equal the water diffusion rate. Comparing the results at different infiltration rates, for which $k$ is assigned $1 \mathrm{e}-6 \mathrm{~m} / \mathrm{s}$ and $2 \mathrm{e}-6 \mathrm{~m} / \mathrm{s}$ (Geotechdata.info, 2013), our

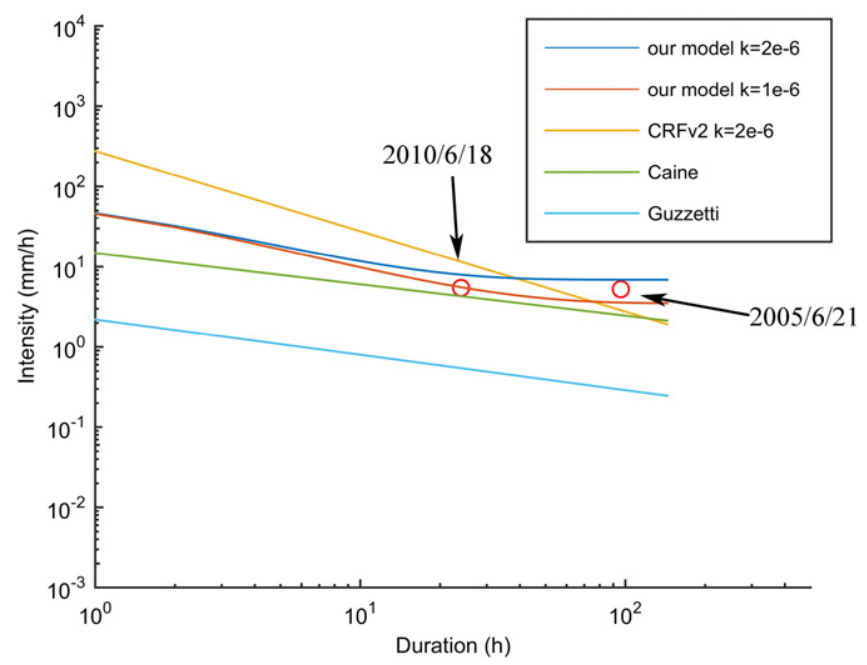

Fig. 4. The hourly intensity-duration thresholds for the Hedangwei landslide estimated using different models (the light blue one is Guzzetti's threshold, the green one is Caine's threshold, the dark blue one is calculated by our model when $k$ is $2 \mathrm{e}-6 \mathrm{~m} / \mathrm{s}$, the red one is calculated with our model when $k$ is $1 \mathrm{e}-6 \mathrm{~m} / \mathrm{s}$ and the yellow one is calculated by CRF-v2 model when $D_{0}$ is equal to $3.1 \mathrm{e}-5 \mathrm{~m}^{2} / \mathrm{s}$ and $k$ is equal to $2 \mathrm{e}-6 \mathrm{~m} / \mathrm{s}$ ). The two circles mark the two sub-slide events of the Hedangwei landslide. 
model shows that the change in rainfall threshold with time is related to the infiltration rate. A lower infiltration rate leads to a lower rainfall threshold for triggering landslides because it becomes difficult for the water to diffuse.

The threshold curves proposed by Guzzetti et al. (2008) and Caine (1980) are also presented in Fig. 4. The threshold predicted using our model is higher than both of threshold curves because these two curves represent lower global bounds of thresholds which take into account all types of landslides in several different geological, geomorphological and climatic conditions. Our model is for a specific landslide and demonstrates that the rainfall threshold curve within a certain range follows the power law. The proposed ID thresholds span a wide range of rainfall durations and intensities. From our model, the form $I=c+\alpha \times D^{\beta}$ is more appropriate, since our model shows that the threshold curve gradually tends towards a constant value on the hourly scale.

However, the rainfall threshold calculated by our model slightly differs from the actual rainfall threshold when $k$ is $1 \mathrm{e}-6 \mathrm{~m} / \mathrm{s}$ or $2 \mathrm{e}-6 \mathrm{~m} / \mathrm{s}$. The inability to capture the actual threshold perfectly is due to our assumption of uniform rainfall and not considering antecedent rainfall. Additionally, in long periods of observation, rainfall intensity represents an "average" value that possibly underestimates the peak of rainfall rate that occurs. For example, on 21st June, 2005, the daily precipitation was $215.2 \mathrm{~mm}$ and the intensity was $8.97 \mathrm{~mm} / \mathrm{h}$, which was much higher than the rainfall threshold of $24 \mathrm{~h}$ calculated by our models. However, considering the total rainfall process, the intensity is $5.23 \mathrm{~mm} / \mathrm{h}$, which marginally predicts a landslide when $k$ equals $2 \mathrm{e}-6 \mathrm{~m} / \mathrm{s}$. In the next section, we will discuss the change in rainfall on the daily scale to solve this inability.

\subsection{Daily rainfall threshold}

Daily rainfall is one of the most important threshold for predicting landslides (Guzzetti et al., 2007). The daily rainfall records of the Hedangwei landslide site are available. The daily rainfall threshold can reveal the influence of antecedent rainfall. Thus, the daily rainfall thresholds for each day can be calculated according to the antecedent rainfall using Eq. (12) and infiltration rate $k$ is assumed to be $2 \mathrm{e}-6 \mathrm{~m} / \mathrm{s}$ according to the soil properties (Geotechdata.info, 2013). In addition, the daily rainfall thresholds were also calculated using the empirical model (Bruce and Clark, 1966; Crozier and Eyles, 1980). The model is

$R_{a_{0}}=k_{s} R_{1}+k_{s}^{2} R_{2}+\ldots+k_{s}^{n} R_{n}$

where $R_{a 0}=$ antecedent rainfall on day $0(\mathrm{~mm}), R_{n}=$ rainfall on the nth day before day $0(\mathrm{~mm})$, and $k_{s}=$ constant decay factor (Crozier and Eyles, 1980; Crozier, 1999; Glade et al., 2000). The decay $k_{s}$ is 0.84 (Crozier and Eyles, 1980). We assume that the daily rainfall and antecedent rainfall play equally important roles in triggering landslides, and a maximum rainfall threshold of $120 \mathrm{~mm}$ is selected in this paper. The estimates of both models and the dates of the two landslide events are illustrated in Fig. 5.

As shown in Fig. 5, the rainfall thresholds for triggering landslides calculated by both models are not fixed values or fixed curves. They will change in response to changes in environmental conditions. Nevertheless, our predictions have less variation compared with those of Crozier's model. An alarm can be declared if the recorded daily rainfall exceeds the predicted daily rainfall threshold. For the Hedangwei landslide site, our model gives four alarms in 2005 (June 19th, 20th, 21st, and May 5) and three alarms in 2010 (June 18th, 23rd and July 7th), while many false alarms are given by Crozier's model (Fig. 5). The four alarms in 2005 correspond to the landslide event on June 21,2005 , while the three alarms in 2010 correspond to the landslide event on June 18,2010. This implies that the daily rainfall thresholds predicted by our model are also reasonable.
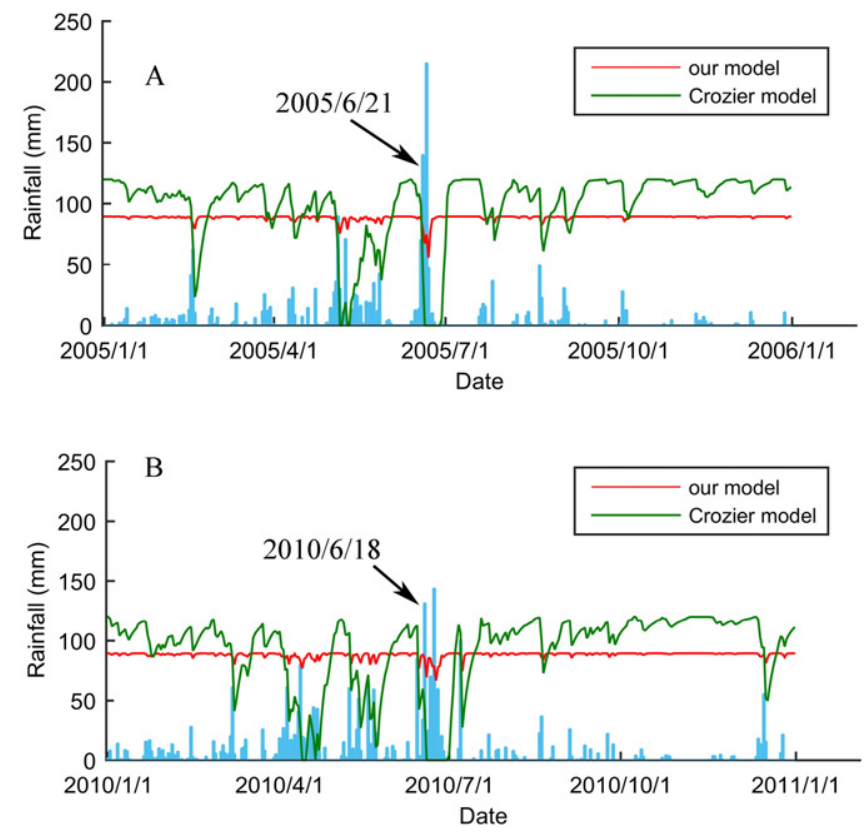

Fig. 5. The daily rainfall threshold of the Hedangwei landslide estimated using different models. The two sub-slide events of the Hedangwei landslide are also indicated (the red one is calculated by our model, the green one is calculated by Crozier's model).

\section{Model application to a region}

We also applied our model to test the ability of the model to predict the rainfall threshold of landslides in a small region. The studied area is approximately $3.04 \mathrm{~km}^{2}$, located around the Caiyuan Village, Nanping City, Fujian Province, China (Fig. 6). The Caiyuan catchment is mainly characterized by metamorphic and sedimentary rocks from the 1:500,000 geological map, and a soil thickness of approximately 2-4 $\mathrm{m}$. The average annual rainfall in this area is approximately $1775 \mathrm{~mm}, 70 \%$ of which occurs during the rainy season from May to June. Heavy rainfall struck this area from June 14th to 24th, 2010 and caused a large number of landslides (Fig. 6). This event has a cumulative rainfall and a maximum rainfall intensity of $350 \mathrm{~mm}$ and $23 \mathrm{~mm} / \mathrm{h}$, respectively.

Most landslides are shallow landslides that occurred on the residual soil. The typical soil parameters of residual soil were adopted in our model. These parameters are assumed to be homogeneous in the studied area according to the soil properties (Table 2). A uniform value of $2 \mathrm{~m}$ was chosen as the depth of the sliding surface because most of the landslides in this area are shallow landslides. The rainfall threshold in the Caiyuan area is estimated under the uniform rainfall assumption. The slope of each cell is calculated using a $5 \mathrm{~m}$ DEM.

The rainfall threshold for each cell can be estimated using Eq. (13). Note that the spatial variation of thresholds in our study is solely derived from the variation of slope angle among different cells. In Fujian Province, 6 hour rainfalls are commonly recorded by rain gauges. Therefore, we determined thresholds (average rainfall) for $6 \mathrm{~h}$ of uniform rainfall.

According to the records of the local rain gauge station, the maximum mean rainfall intensity for 6 hour rainfall events during June 14th and 24th, 2010 is approximately $14 \mathrm{~mm} / \mathrm{h}$. Therefore, we classified the studied area into two categories based on the threshold: lower and larger than $14 \mathrm{~mm}$ (Fig. 7). Then, regarding this rainfall event, the cells with a threshold lower than $14 \mathrm{~mm} / \mathrm{h}$ are considered to be unstable, while those with thresholds greater than $14 \mathrm{~mm} / \mathrm{h}$ are stable. The unstable areas account for $0.18 \mathrm{~km}^{2}$ in total. This value approximates the 


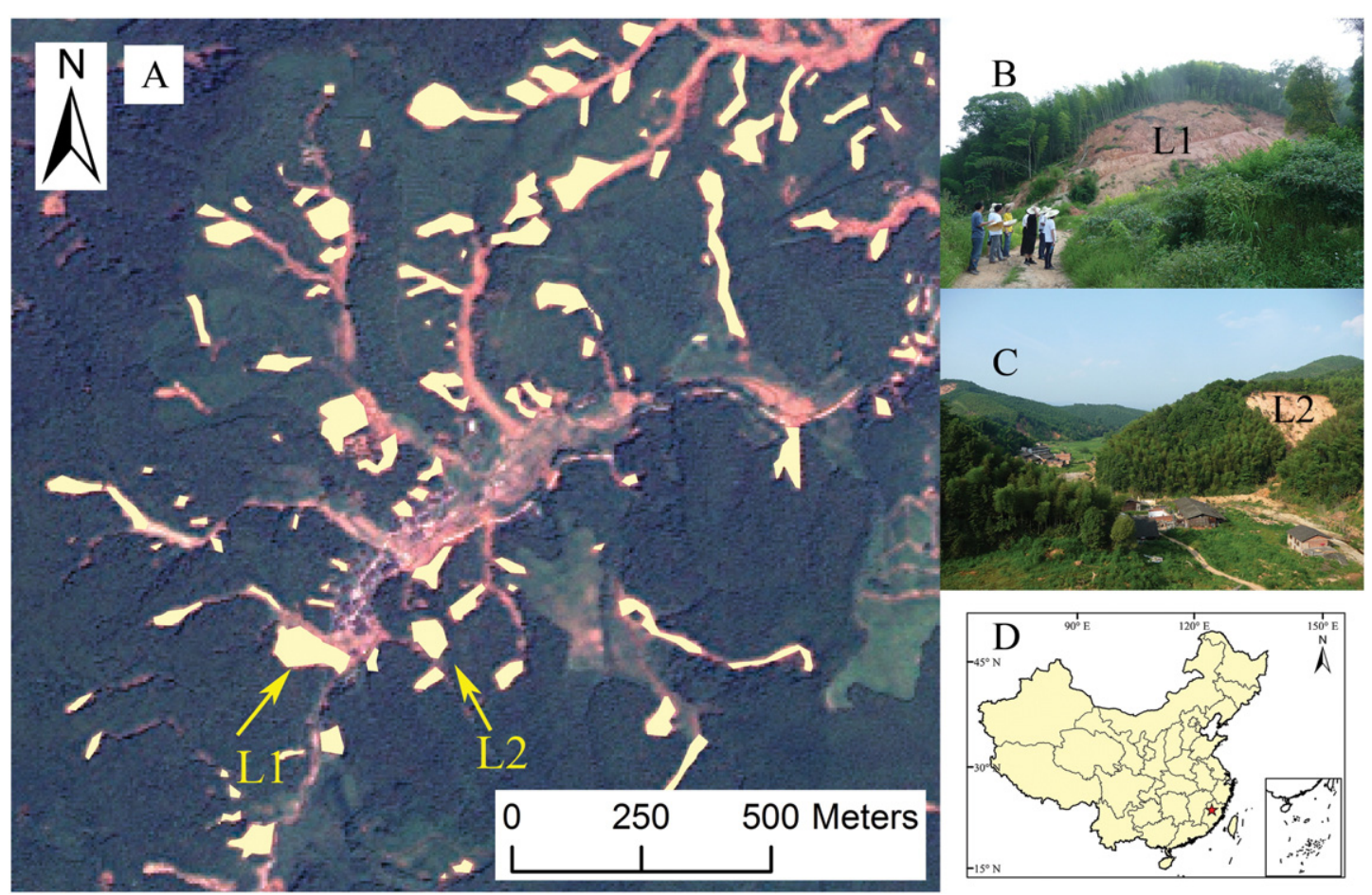

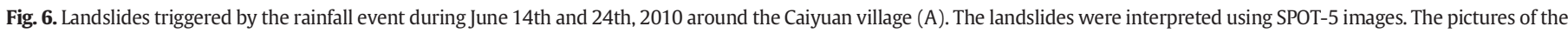
two typical landslides indicated in (A) are shown in (B) and (C). The location of the Caiyuan village in China is shown in (D). Red star stands for the location of Caiyuan catchment.

area of the landslides that occurred in association with this rainfall event $\left(0.17 \mathrm{~km}^{2}\right)$.

To evaluate the result, the "precision index" $(P I)$ and "accuracy index" (AI) were induced (Grelle et al., 2014). The first index is the precision of the total analysis and the second index describes the accuracy of the analysis. The forms of the indexes are given by:

$P I=\frac{A_{t o t}-A_{p r}}{A_{\text {tot }}-\left(A_{\text {unst }}\right)}$

$A I=\frac{N_{\text {in }}}{N_{\text {tot }}}$

where $A_{t o t}$ is the total area, $A_{p r}$ is the estimated unstable area or the area where the threshold is less than $14 \mathrm{~mm} / \mathrm{h}$ computed by the model, and $A_{\text {unst }}$ is the actual unstable area. A landslide is successfully recognized if within its extent there exists at least one cell with a threshold lower $14 \mathrm{~mm} / \mathrm{h}$. In other words, a landslide is successfully recognized if there exists intersection between this landslide and any area with a threshold lower than $14 \mathrm{~mm} / \mathrm{h}$. The $A I$ has been altered to judge if the landslides are recognized using rainfall threshold. $N_{i n}$ is the number of landslides for which the lowest rainfall threshold is below $14 \mathrm{~mm}$. $N_{\text {tot }}$ is the total number of landslides that have been interpreted. For the

Table 2

Mechanical parameters used in Caiyuan.

\begin{tabular}{llllllll}
\hline Study case & $c^{\prime \mathrm{a}}(\mathrm{kPa})$ & $\varphi^{\mathrm{b}}\left({ }^{\circ}\right)$ & $G s^{\mathrm{c}}$ & $n^{\mathrm{d}}$ & $s_{r}{ }^{\mathrm{e}}$ & $r_{w}{ }^{\mathrm{f}}\left(10^{4} \mathrm{~N} / \mathrm{m}^{3}\right)$ & $k^{\mathrm{g}}\left(10^{-6} \mathrm{~m} / \mathrm{s}\right)$ \\
\hline Caiyuan & 14.0 & 18.0 & 2.7 & 0.46 & 0.83 & 1 & 2 \\
\hline
\end{tabular}

\footnotetext{
a $c^{\prime}$ is cohesion.

b $\varphi$ is friction angle.

c Gs is the specific weight.

d $n$ is the porosity.

e $s_{r}$ is the degree of saturation of the soil.

${ }^{f} r_{w}$ is the unit weight of the water.
}

$\mathrm{g} k$ is infiltration rate. best performance of the model, both indexes were equal to $100 \%$. In this paper, rainfall thresholds are used as a criterion to judge whether an area is stable. PI, which is $100.3 \%$, implies a close estimation to the actual unstable area, and $A I$, which is $62.2 \%$, shows that $62.2 \%$ of landslides have been recognized. Although our model cannot evaluate dangerous zones, the rainfall intensity that leads to landslides can be predicted by our model.

\section{Conclusion}

A physically based rainfall threshold model for triggering landslides is presented in this paper. According to the infinite slope model and Mohr-Coulomb strength criterion, the safety factor of a landslide is determined by the dimensionless thickness of the saturated layer $(m)$. A rainfall infiltration model adopting Darcy's law is used to calculate the $m$ in our model. A landslide may occur when the rainfall intensity leads to a value of $m$ that exceeds the threshold value. A specific landslide and a small region were selected for validating the physically based model.

The proposed model is capable of determining both the hourly and daily rainfall thresholds. In particular, it has the advantage of being able to determine the daily rainfall threshold for an area that lacks a landslide inventory and where it is difficult for the empirical models to deploy. The modeling results suggest that the hourly rainfall threshold will obey a power law relationship for short rainfall durations but tends to reach a stable value for longer durations. Therefore, the form $I=c+\alpha \times D^{\beta}$ is more appropriate for the results calculated by our model.

The model is also applied to a typical landslide region in Fujian Province, southeast China. The landslide distribution predicted by the model is comparable with the interpretation of high-resolution satellite imagery, which suggests that the proposed physically based model also effectively determines rainfall thresholds for triggering regional landslides. 


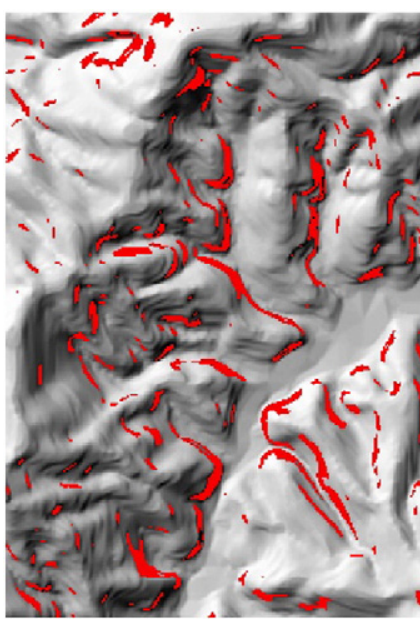

Rainfall threshold $(\mathrm{mm} / \mathrm{h})$

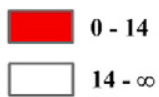

$14-\infty$
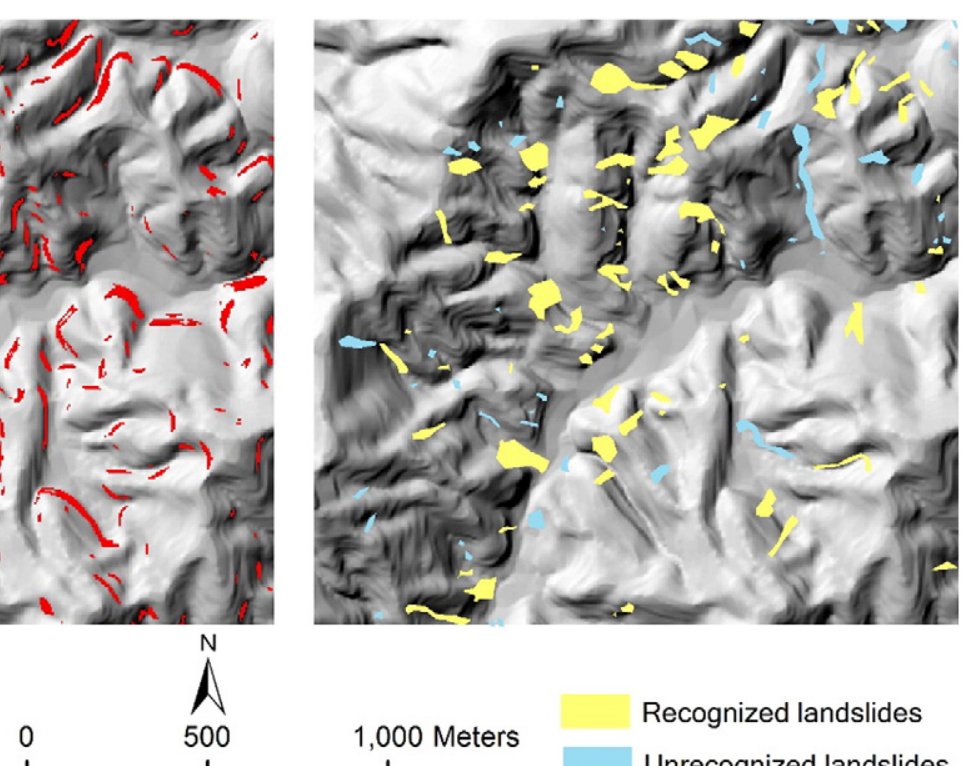

1,000 Meters

\section{Recognized landslides}

Unrecognized landslides

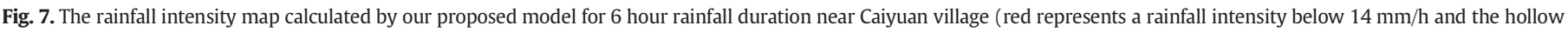

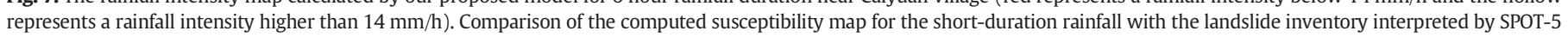
after the $6 \cdot 13$ storm events (yellow represents landslides that have been recognized by our model and blue represents landslides that have not been recognized).

The rainfall threshold for triggering landslides is not a fixed value or a fixed line for triggering landslides. It changes in response to changes in environmental conditions. Future physically based coupled models should take such changes into account, which are expected to contribute to the establishment of practical early warning systems.

\section{Acknowledgments}

This research was supported by the Opening Fund of the Fujian Provincial Key Laboratory of Geological Hazards (no. FJKLGP2012K003), National Natural Science Foundation of China (no. 41072241) and One Hundred Talents Program of Chinese Academy of Sciences (no. A1055). The authors also wish to thank the Fujian Centre for Geological Environment Monitoring for SPOT images and relevant data. Mr. Zhiwei Wang is particularly appreciated for helping us prepare the landslide dataset in the Xiayang-Wangtai area.

\section{References}

Aleotti, P., 2004. A warning system for rainfall-induced shallow failures. Eng. Geol. 73, 247-265.

Baum, R., Savage, W., Godt, J., 2002. TRIGRS-a Fortran program for transient rainfall infiltration and grid-based regional slope-stability analysis. USGS Open File Report 02-0424, US Geological Survey, Reston, VA (available at: http://pubs.usgs.gov/ of/2002/ofr-02-424 (last access: 21 June 2013), 2002).

Baum, R.L., Coe, J.A., Godt, J.W., Harp, E.L., Reid, M.E., Savage, W.Z., Schulz, W.H., Brien, D.L., Chleborad, A.F., McKenna, J.P., Michael, J.A., 2005. Regional landslide-hazard assessment for Seattle, Washington, USA. Landslides 2, 266-279.

Bell, F.G., Maud, R.R., 2000. Landslides associated with the colluvial soils overlying the Natal Group in the greater Durban region of Natal, South Africa. Environ. Geol. 39, 1029-1038.

Bruce, J.P., Clark, R.H., 1966. Introduction to Hydrometeorology. Pergamon Press, 317 pp.

Caine, N., 1980. The rainfall intensity-duration control of shallow landslides and debris flows. Geogr. Ann. A 62, 23-27.

Chang, K.T., Chiang, S.H., Chen, Y.C., Mondini, A.C., 2014. Modeling the spatial occurrence of shallow landslides triggered by typhoons. Geomorphology 208, 137-148.

Crozier, M.J., 1999. Prediction of rainfall-triggered landslides: a test of the antecedent water status model. Earth Surf. Process. Landf. 24, 825-833.

Crozier, M., Eyles, R., 1980. Assessing the Probability of Rapid Mass Movement, 1980.

Floris, M., Bozzano, F., 2008. Evaluation of landslide reactivation: a modified rainfall threshold model based on historical records of rainfall and landslides. Geomorphology $94,40-57$.
Fredlund, D.G., Rahardjo, H., 1993. Soil Mechanics for Unsaturated Soils. John Wiley \& Sons.

Geotechdata.info, 2013. Soil void ratio. http://geotechdata.info/parameter/permeability. html (as of October 7, 2013).

Glade, T., Crozier, M., Smith, P., 2000. Applying probability determination to refine landslide-triggering rainfall thresholds using an empirical "Antecedent Daily Rainfall Model". Pure Appl. Geophys. 157, 1059-1079.

Grelle, G., Soriano, M., Revellino, P., Guerriero, L., Anderson, M.G., Diambra, A., Fiorillo, F., Esposito, L., Diodato, N., Guadagno, F.M., 2014. Space-time prediction of rainfallinduced shallow landslides through a combined probabilistic/deterministic approach, optimized for initial water table conditions. Bull. Eng. Geol. Environ. 73, 877-890.

Guzzetti, F., Peruccacci, S., Rossi, M., Stark, C.P., 2007. Rainfall thresholds for the initiation of landslides in central and southern Europe. Meteorog. Atmos. Phys. 98, 239-267.

Guzzetti, F., Peruccacci, S., Rossi, M., Stark, C.P., 2008. The rainfall intensity-duration control of shallow landslides and debris flows: an update. Landslides 5, 3-17.

Iverson, R.M., 2000. Landslide triggering by rain infiltration. Water Resour. Res. 36, 1897-1910.

Kim, D., Im, S., Lee, S.H., Hong, Y., Cha, K.S., 2010. Predicting the rainfall-triggered landslides in a forested mountain region using TRIGRS model. J. Mt. Sci. Engl. 7, 83-91.

Liao, Z.H., Hong, Y., Kirschbaum, D., Adler, R.F., Gourley, J.J., Wooten, R., 2011. Evaluation of TRIGRS (transient rainfall infiltration and grid-based regional slope-stability analysis)'s predictive skill for hurricane-triggered landslides: a case study in Macon County, North Carolina. Nat. Hazards 58, 325-339.

Martelloni, G., Segoni, S., Fanti, R., Catani, F., 2012. Rainfall thresholds for the forecasting of landslide occurrence at regional scale. Landslides 9, 485-495.

Montrasio, L., Valentino, R., 2008. A model for triggering mechanisms of shallow landslides. Nat. Hazards Earth Syst. 8, 1149-1159.

Montrasio, L., Valentino, R., Losi, G.L., 2009. Rainfall-induced shallow landslides: a model for the triggering mechanism of some case studies in Northern Italy. Landslides 6 , 241-251.

Montrasio, L., Valentino, R., Losi, G.L., 2012. Shallow landslides triggered by rainfalls: modeling of some case histories in the Reggiano Apennine (Emilia Romagna Region, Northern Italy). Nat. Hazards 60, 1231-1254.

Pack, R., Tarboton, D., Goodwin, C., 1998. The SINMAP Approach to Terrain Stability Mapping. pp. 21-25.

Peres, D.J., Cancelliere, A., 2014. Derivation and evaluation of landslide triggering thresholds by a Monte Carlo approach. Hydrol. Earth Syst. Sci. Discuss. 11, 2759-2794.

Salciarini, D., Godt, J.W., Savage, W.Z., Baum, R.L., Conversini, P., 2008. Modeling landslide recurrence in Seattle, Washington, USA. Eng. Geol. 102, 227-237.

Salciarini, D., Tamagnini, C., Conversini, P., Rapinesi, S., 2012. Spatially distributed rainfall thresholds for the initiation of shallow landslides. Nat. Hazards 61, 229-245.

Terhorst, B., Kreja, R., 2009. Slope stability modelling with SINMAP in a settlement area of the Swabian Alb. Landslides 6, 309-319.

Wu, Y.P., Chen, L.X., Cheng, C., Yin, K.L., Torok, A., 2014. GIS-based landslide hazard predicting system and its real-time test during a typhoon, Zhejiang Province, Southeast China. Eng. Geol. 175, 9-21. 